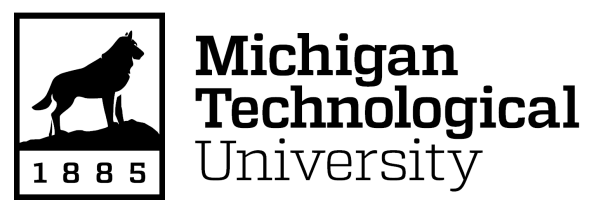

Michigan Technological University Digital Commons @ Michigan Tech

\title{
Uncovering the effect of selected moderators on the disconfirmation-satisfaction relationship: A meta-analytic approach
}

Debi P. Mishra

Junhong Min

Michigan Technological University, jmin@mtu.edu

Follow this and additional works at: https://digitalcommons.mtu.edu/business-fp

Part of the Business Commons, and the Social and Behavioral Sciences Commons

\section{Recommended Citation}

Mishra, D. P., \& Min, J. (2013). Uncovering the effect of selected moderators on the disconfirmationsatisfaction relationship: A meta-analytic approach. Innovative Marketing, 9(2), 7-17.

Retrieved from: https://digitalcommons.mtu.edu/business-fp/226

Follow this and additional works at: https://digitalcommons.mtu.edu/business-fp

Part of the Business Commons, and the Social and Behavioral Sciences Commons 


\section{"Uncovering the effect of selected moderators on the disconfirmation-satisfaction relationship: a meta-analytic approach"}
AUTHORS
Debi P. Mishra, Junhong Min

Debi P. Mishra and Junhong Min (2013). Uncovering the effect

ARTICLE INFO of selected moderators on the disconfirmation-satisfaction relationship: a meta-analytic approach. Innovative Marketing, 9(2)

(c) The author(s) 2017. This publication is an open access article. 
Debi P. Mishra (USA), Junhong Min (USA)

\title{
Uncovering the effect of selected moderators on the disconfirmation- satisfaction relationship: a meta-analytic approach
}

\begin{abstract}
Customer satisfaction occupies a central role in marketing. Not surprisingly, researchers have produced an impressive body of literature that focuses on the causes and consequences of satisfaction. The antecedents of satisfaction have been investigated primarily through the disconfirmation paradigm which holds that satisfaction is the result of conscious mental accounting comparisons undertaken by customers. Furthermore, empirical findings of the disconfirmation-satisfaction link, which are broadly congruent, suggest that when performance conforms to or exceeds initial expectations, a mental state of positive disconfirmation ensues, leading to satisfaction. Despite this insight, a major gap in our understanding concerns lack of generalizability of the disconfirmation model. Specifically, most studies have been conducted in the physical goods setting, thereby raising concerns about the applicability of this model for service exchanges which are more commonplace today. Services differ from goods with respect to intrinsic properties and the manner of delivery. As such, it is possible that the processes underlying customers' satisfaction judgments will differ between goods and services. To investigate generalizability of the disconfirmation paradigm, this paper reports the results of a meta-analysis that the incorporates effect of four moderating variables, i.e., (a) good or service; (b) measure of expectation; (c) definition of satisfaction; and (d) satisfaction scale, on the focal relationship between disconfirmation and satisfaction. The findings suggest that the effect of disconfirmation on satisfaction is weaker for services than it is for physical goods. By including other moderator variables in the analysis, we find that there is sufficient residual variance (in excess of 50\%) to warrant further investigation of the expectationdisconfirmation paradigm. Implications of this research for theory development and the scope for further research are discussed.
\end{abstract}

Keywords: customer satisfaction, disconfirmation, meta-analysis.

\section{Introduction}

Customer satisfaction occupies a central position in marketing. Embedded within the buyer-seller exchange paradigm, the marketing discipline posits that firm profitability and productivity are direct consequences of customer satisfaction (Bagozzi, 1975; Gummerus, 2013; Vargo and Lusch, 2004). Over the years, a considerable body of research has conclusively demonstrated the effect of customer satisfaction on profits (Winkler and Shwaiger, 2011), stock prices (Fornell et al., 2006; Ivanov and Wintoki, 2013), shareholder value (Grewal et al., 2010), market share (Hays and Hill, 2009), and loyalty (Bauman et al., 2012; Flint, Blocker, and Boutin, 2011). Not surprisingly, firms use a variety of tools and metrics to implement optimal customer satisfaction programs (Mintz and Currim, 2012).

In addition to the preceding insights, several papers that aggregate individual results of the link between satisfaction, its antecedents, and its consequences have also appeared in the literature. In particular, researchers have utilized statistical techniques such as meta-analysis (Leuschner, Charvet, and Rogers, 2013; Szymanski and Henard, 2001) and integrative reviews (Hüttinger, Schiele, and Veldman, 2012; Yi, 1990) to create a rich body of literature that provides further insights into the antecedents and consequences of satisfaction.

(c) Debi P. Mishra, Junhong Min, 2013.
In marketing, the confirmation-disconfirmation paradigm has been widely used to study the antecedents of satisfaction. In particular, this model is based on Helson's adaptation level theory (1964), which posits that "one perceives stimuli only in relation to an adapted standard" (p. 461). In other words, expectations about a product's performance form an adaptation level against which subsequent performance is evaluated. Satisfaction is, therefore, the result of a conscious comparison process. Disconfirmation is defined as the deviation of performance from this baseline expectation. Positive disconfirmation (when performance exceeds expectation) leads to satisfaction and delight, while negative disconfirmation results in dissatisfaction. Overall, by using a number of different methodologies such as qualitative case studies (Mishra, 1994), and quantitative modeling such as path analysis and structural equations modeling (Mishra and Min, 2010; Mishra, 2000a), studies have unequivocally established the salience of the disconfirmation paradigm in predicting satisfaction judgments.

Despite insights generated by extant research, two important gaps in our understanding of the disconfirmation-satisfaction relationship still remain unaddressed. First, most studies have focused on how customers make satisfaction judgments with respect to products, with very little attention being directed to uncovering the determinants of satisfaction for services. Since services differ from goods along a number of dimensions such as intrinsic properties 
(Mishra, 2000b; 1994) and the manner of delivery (Mishra, 2006; Mishra, Heide, and Cort 1998), we expect that customers will form satisfaction judgments for services and goods differently. While researchers have recognized that the disconfirmation paradigm may be somewhat limited in understanding satisfaction with services (Churchill and Suprenant, 1982; Oliver, 1980), there is a paucity of research in this area. In particular, we are not sure if the disconfirmation-satisfaction relationship generalizes equally well to services or not. To develop a more balanced view of satisfaction, it is therefore important to study if the disconfirmation paradigm generalizes to service situations in the same way as it does for physical goods.

A second unaddressed gap in our understanding concerns heterogeneity in the strength of the relationship between disconfirmation and satisfaction. For instance, as shown in Table 1 of the Appendix, correlations between disconfirmation and satisfaction range from $0.88(p=.00)$ to null in a set of thirty two studies we considered for analysis. Furthermore, studies differ with respect to the conceptualization (affect vs. mixed) and measurement (single item vs. multiple items) of satisfaction and the definition of expectation. Given this heterogeneity, traditional narrative literature reviews cannot explicitly model and account for measurement error and other artifacts while comparing studies. In other words, cumulating research findings on the disconfirmation-satisfaction link requires a more precise statistical approach.

The preceding concerns can be analyzed by using the technique of meta-analysis which provides a quantitative summary of comparisons across studies. Specifically, the goal of meta-analysis is to integrate findings across studies, calculate variation due to artifacts, and estimate the true relationship between variables. If the variability across studies cannot be explained by artifacts (sampling error, measurement error, and restriction-of-range), moderating variables need to be identified for explaining the residual variation. On the other hand, if most of the variability across studies can be explained by artifacts, the results may be generalizable to other settings.

Given the paucity of research that meaningfully investigates generalizability of the disconfirmation paradigm; the purpose of this paper is twofold. First, we conduct a meta-analysis on the relationship between disconfirmation and satisfaction and investigate whether the findings generalize to service situations. Second, we undertake a more indepth study of generalizability by investigating whether selected moderator variables such as the definitions of satisfaction and expectation, and psychometric property of the satisfaction scale can explain observed variability across studies.

This study seeks to make two important contributions to the satisfaction literature. First, it attempts a quantitative integration of published findings on an important relationship in marketing. Such integration is expected to provide a framework for further theory development in the satisfaction area. In particular, the findings are expected to address boundary conditions regarding generalizability of the disconfirmation paradigm. Second, this study blends two promising meta-analytic approaches advocated by Hunter et al. (1982) and Mullen (1989). In particular, the procedure advocated by Mullen (1989) affords the calculation of statistics for estimating publication bias, together with computations of central tendency and assessment of variability through diffuse comparisons.

It may be noted that a number of studies on the disconfirmation paradigm have utilized different conceptualizations of key variables (expectation and disconfirmation). Meta-analysis is extremely sensitive to pooling studies from different conceptual domains (Mullen, 1989). In this analysis, only studies utilizing product related conceptualizations of expectations and subjective measures of disconfirmation are used. This aspect is discussed further under the "judgment calls" section.

This paper is organized as follows. First, we discuss the disconfirmation paradigm and position of the current paper in the context of extant research. Next, we describe the judgment calls (i.e., various subjective criteria) utilized for the meta-analytic procedure. This is followed by a stepwise outline of the meta-analysis and discussion of our results. Finally, limitations of this study and the scope for further research are outlined. We begin by describing the disconfirmation paradigm.

\section{The disconfirmation paradigm of customer satisfaction}

The underlying idea behind the disconfirmation paradigm is intuitive and rather straightforward. In brief, customers judge satisfaction through a process of mental accounting by comparing ex-post performance of a product with ex-ante expectations held about it. When performance conforms to or exceeds initial expectations, a mental state of positive disconfirmation ensues, that in turn, affects satisfaction positively. In contrast, dissatisfaction results from negative disconfirmation, i.e., when performance fall short of baseline expectations. As noted in Figure 1 below, the disconfirmationsatisfaction link has been widely investigated in marketing. In addition, researchers have also studied other pathways through which customer satisfaction 
judgments are formed such as direct independent (expectation $\rightarrow$ satisfaction; performance $\rightarrow$ satisfaction), and indirect mediating (i.e., expectation $\rightarrow$ performance $\rightarrow$ disconfirmation $\rightarrow$ satisfaction) effects (Yi, 1993). Note however, that the role of moderator variables that can affect the focal relationship between disconfirmation and satisfaction has been understudied in the literature.

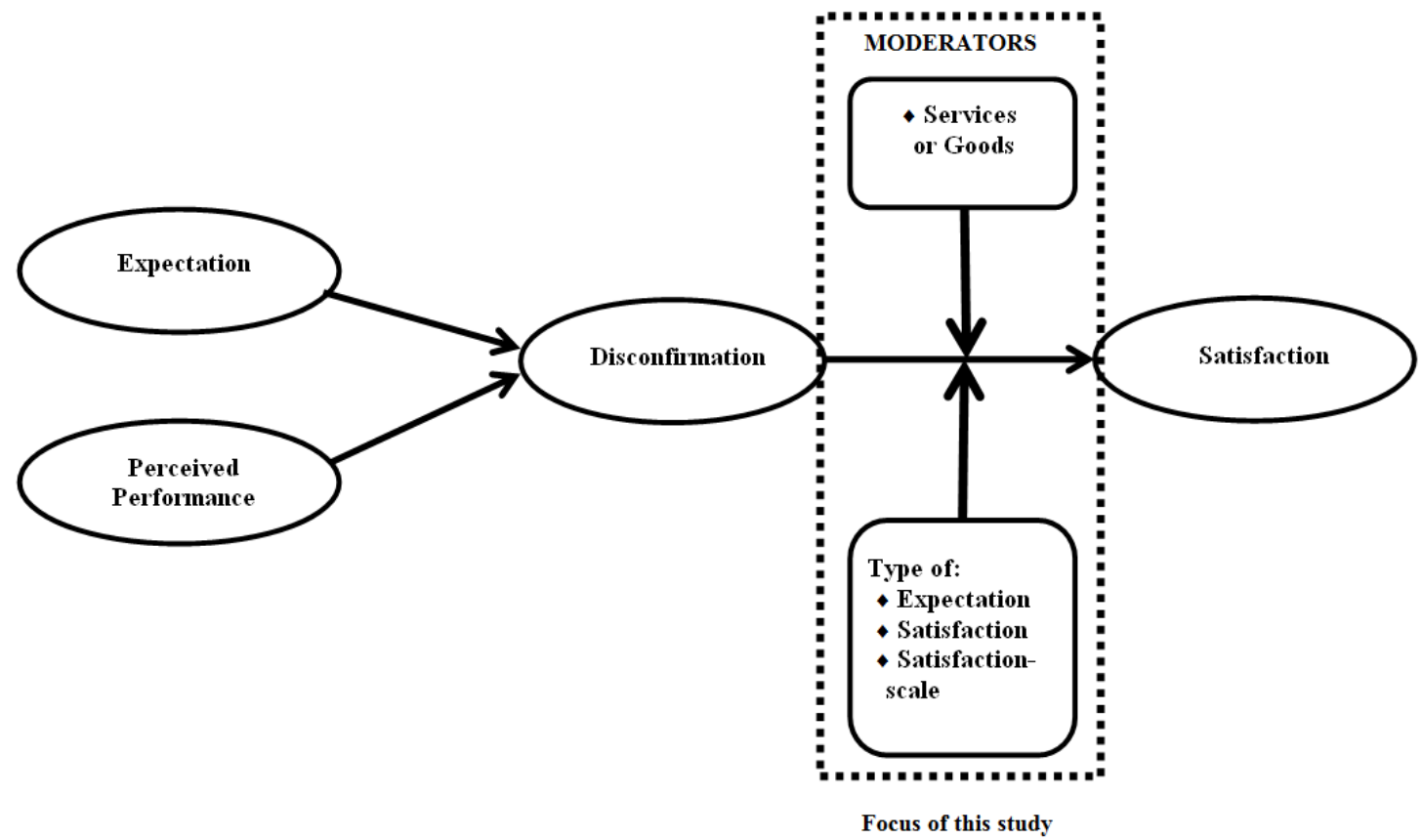

Fig. 1. The disconfirmation paradigm

\section{Judgment calls}

Wanous, Sullivan, and Malinak (1989) re-examined previous meta-analyses in industrial and organizational psychology and reported that "judgment calls really do affect the results of a meta-analysis" (p. 260). Furthermore, they advocated that researchers should think carefully about various judgments and "report the decisions with the greatest detail possible" (p. 263). Following the preceding recommendation, we describe the judgment calls for the present study together with their rationale.

2.1. Defining the domain of research. The domain of research was defined by the independent variable (i.e., disconfirmation of expectations). Specifically, one's initial expectation serves as an adaptation level. Positive disconfirmation (i.e., performance in excess of expectation) leads to satisfaction, while negative disconfirmation (i.e., performance below expectation) leads to dissatisfaction. Two widely researched forms of expectation are (a) predictive (related to product attributes only); and (b) desired (based on norms of performance and past experience). However, Miller (1977) argues that these expectation types may have discriminant validity. In order to select a set of conceptually homogeneous studies, only those articles utilizing expectations related to product and service attributes were selected. For studies reporting multiple results (Prakash, 1984; Swan and Trawick, 1981), the appropriate correlation between disconfirmation of product and service related expectation and satisfaction was considered.

Since there are alternative conceptualizations of the disconfirmation construct, only articles utilizing a subjective measure were selected. Subsumed under this category are the inferred (i.e., difference between expectations and actual performance) and perceived (i.e., subjective or better than - worse than) measures of disconfirmation (Yi, 1990).

Although the study by Churchill and Surprenant (1982) employs an objective measure (performance varied by the researcher) for manipulation checks, disconfirmation has been assessed utilizing subjective (better than - worse than) scales. This study was, therefore, included in the data base.

Finally, both perceived and inferred disconfirmation appears to be measuring the same construct (Swan and Trawick, 1981). However, the inferred type suffers from reliability problems (Prakash, 1984) and may be a weak measure of disconfirmation. Nevertheless, it is a valid measure of disconfirmation, and studies utilizing this measure warrant inclusion in the data base. On the other hand, studies employing the objective form of disconfirmation are not candidates for inclusion, since satisfaction is a subjective, psychological mental state (Yi, 1990).

2.2. Establishing criteria for including studies. The data base consists of published studies (1970-2010). This time period was chosen because the earliest 
empirical articles on the expectation-disconfirmation paradigm appeared around the late seventies (Oliver, $1979,1977)$ while research into the disconfirmation paradigm started slowing down in the early 1990's given the emergence and gradual dominance of the service quality construct in marketing (Parasuraman et al., 2004, 1999). Furthermore, only statistically independent studies were included. In other words, duplication from the same data base was avoided. Finally, outcomes of statistically independent subsamples in the same study (Oliver, 1980; Churchill and Surprenant, 1982) were considered as distinct studies (Mullen, 1989).

2.3. Searching for relevant studies. A computer search on ABI INFORM with satisfaction as the keyword yielded 130,610 articles published between 1970 and 2013. To keep the search results tractable and manageable, we narrowed the search by using the keyword "satisfaction and disconfirmation". This approach yielded a total of 2522 articles published between 1970 and 2013. However, not every study provided a quantitative estimate of the disconfirmation-satisfaction relationship. Furthermore, many studies did not report a relevant useable statistic for the focal relationship. A thorough manual inspection of articles resulted in 32 empirically usable articles published during the 1970-2010 time period (see Appendix, Table 1)

2.4. Reconstruction of missing values. Nonsignificant correlations were assigned a $p$-value of 0.5 (Mullen, 1989), whereas significant correlations without the exact value (e.g., $p<0.05$ or $p<0.01$ ) were fixed at the upper limit $(0.05$ or 0.01$)$ as suggested by Mullen (1989). Following Hunter et al. (1982), beta values were not used as proxies for correlation coefficients. Instead, a transformation of $p$ to $r$ was used. Finally, for studies reporting multiple results (Swan and Trawick, 1981), the lowest value of $r$ (or $p$ ) was adopted for conservative results.

\section{A stepwise procedure for the meta-analytic calculations}

3.1. Common metric for significance levels and effect sizes. 3.1.1. Procedure. The two dimensions of a study's outcome (i.e., the significance level and the effect size) are converted into a common metric of $Z_{\text {Fisher }}$ 's for effect sizes and Z's for significance levels. The use of $Z_{\text {Fisher }}$ (instead of $r$ ) circumvents nonlinearity of the $r$ metric at extreme values and affords meaningful comparisons across studies (James, Demaree, and Mulaik, 1986; Mullen, 1989). For studies which do not report $Z$ 's and $Z_{\text {Fisher }}$ 's, appropriate transformations (of $\chi^{2}, t, F$, and $p$, into $Z, r$, and $Z_{\text {Fisher }}$ ) as per Mullen (1989, pp. 43-44) were used.
3.2. Measures of central tendency for $Z$ and $Z_{\text {Fisher. Step }} 1$. The mean significance level across studies $\left(Z_{A v g}\right)$ (Mullen, 1989, p. 71) is given by:

$\left(Z_{A v g}\right)=\left(\sum w_{j} Z_{j}\right) /\left(\sum w_{j}^{2}\right)^{0.5}$,

where $w_{j}$ is the weight assigned to the results of the $j^{\text {th }}$ hypothesis test (usually the sample size), and $Z_{j}$ is the significance level of the $j^{\text {th }}$ hypothesis test. The $p$ value corresponding to $Z_{A v g}$ tests the null hypothesis that the mean significance level across studies is zero.

Step 2. The mean effect size across studies $\left(Z_{F i s h e r}\right.$. Avg) (Mullen, 1989, p. 73) is calculated as:

$\left(Z_{\text {Fisher,Avg }}\right)=\left(\sum w_{j} Z_{\text {Fisher }}\right) /\left(\sum w_{j}\right)$.

Furthermore, $\left(Z_{\text {Fisher, Avg }}\right)$ can be converted into a $r$ or a $d$ (Cohen's $d$; Cohen, 1977). The $p$-value associated with $r$ tests the null hypothesis that the effect size for the typical study is zero, while $d$ 's of $0.10,0.30$, and 0.50 , correspond to small, medium, and large effect sizes respectively (Cohen, 1977).

Step 3. The 95\% confidence interval around $r(r \pm$ $1.96 \sigma_{r} ; \sigma_{r}$ is the standard deviation of $r$ ) that does not include zero provides another test of the preceding null hypothesis $\left(\mathrm{H}_{0}\right.$ : The mean effect size is zero). The variance of $r\left(\sigma_{r}^{2}\right)$ (Hunter, Schmidt, and Jackson, 1982, p. 41) is computed as:

$\sigma_{r}^{2}=\sum\left[N_{i}\left(r_{i}-r_{\text {Avg }}^{2}\right)\right] / \sum N_{i}$,

where $N_{i}$ is the sample size for study $i, r_{i}$ is the correlation in study $i$, and $r_{A v g}$ is defined as:

$r_{\text {Avg }}=\sum\left(N_{i} r_{i}\right) / \sum N_{i}$.

3.3. The file drawer problem. Step 1 . The fail safe number $\left(N_{f s}\right)$ for the significance level indicates the number of studies to which the researcher has no access averaging null results which would bring the combined significance level to non-significance $(p>$ $0.5)$. Large value of this statistic alleviates the problem of non-retrieved studies. Rosenthal (1979) defines $\left(N_{f s}\right)$ for the significance level as:

$N_{f s}=\left(\sum Z_{j} / 1.645\right)^{2}-k$,

where $\left(Z_{j}\right)$ is the significance level for the $j^{\text {th }}$ study, and $k$ is the number of studies. Rosenthal (1984) suggests a minimum value of $N_{f s}$ as $5 k+10$.

Step 2. The fail safe number for effect sizes (Orwin, 1983 ) is:

$N_{f s}=k\left(Z_{\text {Fisher, }, \text { vvg }}-0.1\right) / 0.1$. 
The interpretation of this statistic is identical to that in step 1 above.

3.4. Publication bias. An indication of publication bias is obtained by plotting study outcomes $\left(Z_{\text {Fisher }}{ }^{\prime} s\right)$ against sample sizes $\left(N_{i}^{\prime} s\right)$. An inverted funnel suggests no publication bias (Light and Pillemer, 1984).

3.5. Diffuse comparison of significance levels and effect sizes. Step 1. A test of the null hypothesis that the significance level does not differ across studies is provided by the $\chi^{2}$ test (Mullen, 1989, p. 80). This statistic (for $k-1 d f$ ) is computed as:

$x_{(k-1)}^{2}=\sum\left(Z_{j}-Z_{A v g}\right)^{2}$.

Step 2. The $\chi^{2}$ for the effect size (Mullen, 1989, p. $80)$ is defined as:

$x_{(k-1)}^{2}=\sum\left(N_{j}-3\right)\left(Z_{\text {Fisher }}-Z_{\text {Fisher,Avg }}\right)^{2}$.

Statistical significance of the $\chi^{2}$ tests implies that the variance across studies needs to be computed and accounted for.

3.6. Calculation of uncorrected variance. Step 1 . The uncorrected variance of $r\left(\sigma_{r}{ }^{2}\right)$ is computed as: $\sigma_{r}^{2}=\sum\left[N_{i}\left(r_{i}-r_{A v g}^{2}\right)\right] / \sum N_{i}$,

where $r_{A v g}=\sum\left(N_{i} r_{i}\right) / \sum N_{i}$.

Step 2. The computed variance is then tested for statistical significance ( $\mathrm{H} 0$ : The true variance in the population is zero) through the $\chi^{2}$ test which is defined as:

$$
x_{(k-1)}^{2}=\sum N_{i} /\left(1-r_{A v g}^{2}\right) \sigma_{r}^{2},
$$

3.7. Correction of variance for sampling error. Procedure. An estimate of the population variance across studies $\left(\sigma_{p}{ }^{2}\right)$ is provided by $\sigma_{r}{ }^{2}$ ) (See step 1 , section 3.5). This estimate of the observed variation in sample correlations is confounded by sampling error. Specifically, if $\left(\sigma_{e}^{2}\right)$ denotes the sampling error, then $\sigma_{p}^{2}=\sigma_{r}^{2}-\sigma_{e}^{2}$ (Hunter et al., 1982). The sampling error is given by the following equation, $\sigma_{e}^{2}=\left(1-r_{A v g}^{2}\right)^{2} / \sum N$.

3.8. Correction of variance for measurement error. Step 1. Since all studies do not report reliabilities for the independent $\left(r_{x x}\right)$ and the dependent variable $\left(r_{y y}\right)$, first an average adjustment is computed as per Hunter et al. (1982, p. 83) as follows:

$a=\sum\left(r_{x x}\right)^{0.5} / k$,

$b=\sum\left(r_{y y}\right)^{0.5} / k$,

where $k$ is the number of studies reporting the reliability coefficient.

Step 2. The adjusted variances of the dependent and the independent variables are calculated as:

$\sigma_{a}^{2}=\sum\left(r_{x x}-a\right)^{2} / k$,

$\sigma_{b}^{2}=\sum\left(r_{y y}-b\right)^{2} / k$,

Step 3. The population correlation corrected for measurement error is calculated as $\rho_{T U}=r($ as in step B2, section 3.2)/ab. At this step a new confidence interval around $r$ may be constructed.

Step 4. The variance of the population correlation adjusted for measurement error is given by:

$\sigma_{p T U}^{2}=\left[\sigma_{r}^{2}-\rho_{T U}^{2}\left(a^{2} \sigma_{b}^{2}+b^{2} \sigma_{a}^{2}\right)\right] /\left(a^{2} b^{2}\right)$.

Step 5. The variance due to measurement error is given by:

$\sigma_{\text {Meas }}^{2}=\sigma_{p T U}^{2}\left(a^{2} \sigma_{b}^{2}+b^{2} \sigma_{a}^{2}\right)$.

Step 6. The true population variance after adjusting for sampling error and measurement error is calculated from the following relationship:

$\sigma_{p}^{2}=\sigma_{r}^{2}-\sigma_{e}^{2}-\sigma_{\text {Meas }}^{2}$.

3.9. Correction of variance for restriction-ofrange. If there is enough variance left at step 6 (section 3.8) after correcting for measurement error, the next step is to correct this variance for restriction-of-range. In the present analysis, only 8 studies have reported standard deviation for the independent variable (disconfirmation). An inspection of these values indicates that restriction-ofrange is not a severe problem (refer to discussion under the "Results" section). The interested reader is also directed to Hunter et al. (1982) for computational details.

3.10. Moderator variable analysis. If a significant amount of variance remains even after correcting for all artifacts, the final step is to search for potential moderator variables to explain these differences. The following steps are adopted from Hunter et al. (1982) and Mullen (1989). 
Table 1. Moderator variable analysis (type of product and definition of expectation).

\begin{tabular}{|c|c|c|c|c|c|}
\hline \multirow{2}{*}{ Findings } & Full data & Type of product & Type of product & Expectation & Expectation \\
\hline & & Durable & Service & $\sum_{B_{i} a_{i}}$ & $\sum_{B_{i}}$ \\
\hline \multicolumn{6}{|l|}{ Central tendencya } \\
\hline$Z$ & $7.721^{*}$ & $4.971^{*}$ & $6.996^{*}$ & $5.005^{*}$ & $6.030^{*}$ \\
\hline$Z_{\text {Fisher }}$ & 0.266 & 0.316 & 0.237 & 0.284 & 0.235 \\
\hline$r$ & 0.251 & 0.295 & 0.227 & 0.269 & 0.224 \\
\hline $95 \%$ confidence interval & $0.0708,0.4320$ & $-0.033,0.6236$ & $0.0880,0.3656$ & $-0.009,0.54$ & $0.094,0.353$ \\
\hline Cohen's d & 0.519 & 0.617 & 0.466 & 0.559 & 0.459 \\
\hline \multicolumn{6}{|l|}{ File drawer problemb } \\
\hline$N_{t s}($ sig. level) & 640 & 93 & 203 & .52 & 234 \\
\hline$N_{\text {ts }}$ (effect size) & 37 & 20 & 16 & 10 & 21 \\
\hline \multicolumn{6}{|l|}{ Diffuse comparisons ${ }^{c}$} \\
\hline Sig. level $\left(\chi^{2}, d f, p\right)$ & $755.14,21^{*}$ & $93.63,8^{*}$ & $259.73,10^{*}$ & $32.61,4^{*}$ & $290.07,14^{*}$ \\
\hline Sig. level $\left(\chi^{2}, d f, p\right)$ & $153.64,21$ * & $90.97,8^{*}$ & $41.14,10^{*}$ & $21.73,4^{*}$ & $101.06,14^{*}$ \\
\hline \multicolumn{6}{|l|}{ Variance } \\
\hline Uncorrected variance in $r$ & 0.0084900 & 0.02814 & 0.00501 & 0.02028 & 0.00438 \\
\hline Sampling error variance & 0.0040300 & 0.00302 & 0.00544 & 0.00503 & 0.00377 \\
\hline Measurement error variance & 0.0000784 & 0.00109 & - & - & 0.00005 \\
\hline Corrected variance & 0.0043800 & 0.02402 & 0.00000 & 0.01525 & 0.00055 \\
\hline$\%$ variance (sampling error) & 47.46 & 10.73 & 100 & 31.36 & 86.07 \\
\hline$\%$ variance (mean error) & 0.930 & 3.910 & 0.000 & 0.000 & 1.25 \\
\hline$\%$ variance (unexplained) & 51.61 & 85.36 & 0.000 & 68.64 & 12.68 \\
\hline
\end{tabular}

Notes: ${ }^{a}$ Mean outcome values. ${ }^{\mathrm{b}}$ The number of studies (averaging null results) which would bring the current significance level (or effect size) to non-significance. ${ }^{\mathrm{c}}$ Tests the null hypothesis that the study outcome is invariant ${ }^{*} p<0.01$.

Step 1. For discrete independent variables (gender of respondent, type of scale), a sub-group analysis may be conducted to determine potential moderators (Hunter et al., 1982). Specifically, inspecting the mean and variance of the effect size within subgroups provides an indication of the moderating effect. Alternatively, the point-biserial correlation between $Z_{F i s h e r}$ and the discrete variables may be computed (Mullen, 1989). However, the $p$ value associated with this correlation is not appropriate for statistical testing (Mullen, 1989).

Step 2. For continuous independent variables (i.e., sample size, year of study), a regression analysis utilizing $Z_{\text {Fisher }}$ as the dependent variable may be undertaken (Mullen, 1989).

\section{Results and discussion}

4.1. Central tendency. The null hypothesis of nonsignificance for the average study outcome (for $Z$ and $r)$ are strongly rejected $\left(Z=7.721, p<0.01 ; Z_{\text {Fisher }}=\right.$ $0.266 ; r=0.266, p<0.01)$, thereby confirming a positive relationship between disconfirmation and satisfaction. Further support for this relationship is provided by the $95 \%$ confidence interval for $r(0.078$ to 0.4320 ) and the high value for Cohen's $d(0.519)$.

4.2. File drawer problem and publication bias. The fail safe numbers for the significance level (640) and the effect size (37) suggest that file drawer studies do not pose a severe problem for the present analysis. In other words, 640 studies for the significance level and 37 for the effect size averaging null results would have to be retrieved to overturn the positive correlation observed in the present analysis. Although the funnel plot is not truly inverted, it does not conclusively prove the existence of publication bias, as a large number of studies are required for a reliable plot (Light and Pillemer, 1984).

4.3. Diffuse comparison. The null hypothesis that the significance level (or the effect size) does not differ across studies is rejected $\left(\chi_{21}^{2}=755 ; 14, p<\right.$ 0.01 for $Z ; \chi_{21}^{2}=155 ; 64, p<0.01$ for $r$ ) indicating that there is variability across studies which needs to be computed and explained (see Table 1).

4.4. Variance computations. Table 1 provides the breakdown of the total variance into its constituents. Specifically, $47.46 \%$ of the observed variability is explained by sampling error while $1 \%$ of the variance is explained by measurement error. This leaves $51.6 \%$ of the variance unexplained. In light of this large unexplained variance, the results (i.e., positive relationship between disconfirmation and satisfaction) cannot be generalized. Note however, that adjustments for restriction-of-range were not carried out since only 8 studies have reported the standard deviation for the independent variable (disconfirmation). Of these studies, there is one value in excess of 3 (Prakash, 1984; see Appendix) which implies that restriction-ofrange is not a serious problem. In any case, this artifact may not explain the large proportion of unexplained 
variance. The preceding observation calls for identification and analysis of moderator variables for explaining variability across studies. The following section discusses the moderator variable analysis and results.

4.5. Moderator variable analysis. Six potential moderator variables were identified. The rational for selecting these variables and their impact upon the results of the present study are discussed below.

4.5.1. Goods and services. Studies were grouped into two categories (i.e., durable goods and services). Such a grouping is justified in view of the apparent conceptual distinction between goods and services (Hill, 1986; Vargo and Lusch, 2004). Specifically, services differ from goods with respect to non-standardization, intangibility, and simultaneous production and consumption. These differentiating factors indicate that the evaluation processes and the subsequent influence on satisfaction for services and goods might be different (Mishra, 2000b; 2006; Mishra, Heide and Cort, 1998).

The effect size for durables is higher than that for services (Table 1). Furthermore, $86 \%$ of the variance is unexplained in the durable subgroup while there is no residual variance for the service category ( $100 \%$ explained by sampling error). Note however, that a subgroup analysis for nondurables could not be carried out as there were only two relevant studies.
4.5.2. Expectation measure. Expectation has been measured either as the sum of individual beliefs (Churchill and Surprenant, 1982) or as the sum of belief times evaluation (Oliver and Bearden, 1983). These different yet conceptually similar (cf. Swan and Trawick, 1981) measures may explain variability across studies.

The results (Table 1) show evidence for the superiority of the first measure (i.e., sum of individual beliefs). In particular, $12.68 \%$ of the variance remains to be explained for studies employing this measure of expectation. The comparable figure for the belief times evaluation measure is $68.64 \%$. Expectation definition is therefore an important moderator.

4.5.3. Satisfaction definition. Two categories of definitions have been used in the studies, i.e., (a) satisfaction as an emotional outcome (affect), and (b) satisfaction as a combination of conscious evaluations and affect (i.e., mixed). The latter definition is process oriented and encompasses the entire consumption experience (Yi, 1990). Satisfaction definition is therefore proposed as a moderator.

For studies utilizing the affect definition, $100 \%$ of the variance is explained by sampling error whereas for the mixed category, $89.22 \%$ and $10.78 \%$ of the observed variance are explained by measurement error and sampling error respectively. However, the effect size for the mixed group (0.301) is higher than that for the affect category.

Table 2. Moderator variable analysis (satisfaction)

\begin{tabular}{|c|c|c|c|c|c|}
\hline \multirow{2}{*}{ Findings } & Full data & Satisfaction & Satisfaction & Scale & Scale \\
\hline & & Affect & Mixed & Multi-item & Single-item \\
\hline \multicolumn{6}{|l|}{ Central tendencya } \\
\hline$Z$ & $7.721^{*}$ & $4.482^{*}$ & $6.630^{*}$ & $7.970^{*}$ & $3.963^{*}$ \\
\hline$Z_{\text {Fisher }}$ & 0.266 & 0.231 & 0.326 & 0.303 & 0.214 \\
\hline$r$ & 0.251 & 0.222 & 0.301 & 0.282 & 0.208 \\
\hline $95 \%$ confidence interval & $0.0708,0.4320$ & $0.101,0.3438$ & $-0.089,0.693$ & $0.029,0.54$ & $0.017,0.399$ \\
\hline Cohen's $d$ & 0.519 & 0.456 & 0.632 & 0.588 & 0.424 \\
\hline \multicolumn{6}{|l|}{ File drawer problemb } \\
\hline$N_{\text {ts }}($ sig. level) & 640 & 46 & 153 & 381 & 28 \\
\hline$N_{\text {is }}($ effect size) & 37 & 7 & 25 & 33 & 7 \\
\hline \multicolumn{6}{|l|}{ Diffuse comparisons ${ }^{c}$} \\
\hline Sig. level $\left(\chi^{2}, d f, p\right)$ & $755.14,21$ * & $22.96,10^{* *}$ & $254.41,15^{*}$ & $571.71,15^{*}$ & $38.14,5^{*}$ \\
\hline Sig. level $\left(\chi^{2}, d f, p\right)$ & $153.64,21$ * & $11.56,10^{* *}$ & $106.04,15^{*}$ & $122.92,15$ * & $21.96,5^{*}$ \\
\hline \multicolumn{6}{|l|}{ Variance } \\
\hline Uncorrected variance in $r$ & 0.0084900 & 0.00381 & 0.03977 & 0.01656 & 0.00951 \\
\hline Sampling error variance & 0.0040300 & 0.00654 & 0.00429 & 0.00482 & 0.00278 \\
\hline Measurement error variance & 0.0000784 & - & 0.09298 & 0.00009 & - \\
\hline Corrected variance & 0.0043800 & 0.00000 & 0.00000 & 0.01165 & 0.00670 \\
\hline$\%$ variance (sampling error) & 47.46 & 100 & 10.78 & 29.11 & 29.23 \\
\hline$\%$ variance (mean error) & 0.930 & 0.000 & 89.22 & 0.550 & 0.000 \\
\hline$\%$ variance (unexplained) & 51.61 & 0.000 & 0.000 & 70.35 & 70.77 \\
\hline
\end{tabular}

Notes: ${ }^{\mathrm{a}}$ Mean outcome values, ${ }^{\mathrm{b}}$ The number of studies (averaging null results) which would bring the current significance level (or effect size) to non-significance; ${ }^{*} p<0.01, * * p<0.05$. $^{\mathrm{c}}$ Tests the null hypothesis that the study outcome is invariant. 
Satisfaction measure. Multi item measures are more reliable than single item measures (Nunnally, 1978). Since these measures appear in the database, the moderating effect of the type of satisfaction scales is hypothesized.

The residual variance for either group is about $70 \%$ (see Table 2). However, as expected, the effect size for the multi-item group $\left(Z_{\text {Fisher }}=0.303\right)$ is higher than for the single-item studies $\left(Z_{\text {Fisher }}=0.214\right)$. The weak moderating effect may be caused by the relatively fewer studies for the single-item group (5).

Year of study and sample size. Year of study is a potential moderator because improvements in methodology and theoretical advancement over time may affect the typical study outcome. Sample size is considered a moderator because it influences the effect size.

A multiple regression of $Z_{\text {fisher }}$ against year of study and sample size yields an insignificant $R^{2}$ and slopes $\left(R^{2}=0.005, F=0.05, p=0.95 ; \beta_{N}=.323, p=.75 ; \beta_{\text {year }}\right.$ $=.0026, p=.99)$. This result may be due to the small sample size (32) of the meta-analytic data-base.

\section{Conclusions and limitations}

Our findings suggest that the effect size for the relationship between disconfirmation and satisfaction is fairly strong $(r=0.251)$. Furthermore, the file drawer calculations indicate that a relatively large number of studies is needed to overturn the results of the present study. After adjusting for sampling error and measurement artifacts, more than $50 \%$ of the observed variance remains to be explained.

Separate meta-analyses revealed the existence of four moderators, i.e., (a) the use of durables or services for studying satisfaction; (b) the definition of expectation; (c) the definition of satisfaction; and (d) the type of scale employed for measuring satisfaction. Given the presence of moderating variables, the relationship between disconfirmation and satisfaction cannot be generalized to all settings.

Further research should pay attention to these moderating variables and explore other potential moderators in order to uncover the true nature of the relationship between disconfirmation and satisfaction. For example, consider the large amount of unexplained variation for the durable goods category. As noted earlier, the effect size for durables is higher than that for services and $86 \%$ of the variance is unexplained in the durable subgroup. The main implication of this finding is that when it comes to consumer durables, customers might employ a different psychological heuristic to form disconfirmation perceptions. For example, as noted by Vargo and Lusch (2004), the service dominant logic is a useful way to conceptualize how durable goods can undergo a psychological transformation in consumers' minds and approximate an ongoing service relationship. As such, consumers' evaluative process might be different than a one shot evaluation of product performance. For example, service considerations imply an ongoing relationship with the customer where beliefs are being constantly updated based upon dynamic performance. Furthermore, emerging research has documented the existence of secondary agency relationships (Mishra, Heide, and Cort, 1998) that affect the delivery of service. In summary, although research on the link between disconfirmation and satisfaction has been eclipsed by service quality research, a retrospective look at the disconfirmation model may yield additional insights into the conceptualization of customer satisfaction.

This study needs to be evaluated in light of certain limitations. First, the small number of studies might have affected the sub-group analyses. To this extent, a thorough investigation of all possible moderator variables was not possible. For instance, sex of the respondent, the type of survey method used, and the nature of the disconfirmation measure employed (i.e., objective vs subjective) may be potential moderators. Second, incomplete data (for measurement error and restriction-of-range) precluded a more rigorous assessment of measurement artifacts (though average corrections for measurement were used). Finally, the various judgment calls employed might have influenced the results, although every attempt was made to reconstruct missing values in a careful and consistent fashion. A desirable approach would have entailed obtaining missing information by contacting the authors (i.e., requesting the correlation matrices, reliabilities, and standard deviations of the independent variable).

\section{References}

1. Barbeau, J.B. (1985). Predictive and Normative Expectations in Consumer Satisfaction: A Utilization of Adaptation and Comparison Levels in a Unified Framework, in Consumer Satisfaction, Dissatisfaction, and Complaining Behavior, H. Keith Hunt and Ralph R. Day (eds), Bloomington Indiana: Indiana University.

2. Baumann, C., Elliott, G. \& Burton, S. (2012). Modeling customer satisfaction and loyalty: survey data versus data mining, Journal of Services Marketing, 26 (3), pp. 148-157.

3. Bagozzi, R.P. (1975). Marketing as Exchange, Journal of Marketing, 38 (October), pp. 77-28.

4. Bearden, W.O., and Teel, J.E. (1983). Selected Determinants of Consumer Satisfaction and Complaint Reports, Journal of Marketing Research, 22(February), pp. 21-28. 
5. Cadotte, E.R., Woodroff, R.B., and Jenkins, R.L. (1987). Expectations and Norms in Models of Consumer Satisfaction, Journal of Marketing Research, 24 (August), pp. 305-314.

6. Churchill, G.A., and Surprenant, C. (1982). An Investigation into the Determinants of Consumer Satisfaction, Journal of Marketing Research, 19 (November), pp. 491-504.

7. Cohen, J. (1977). Statistical Power Analysis for the Behavioral Sciences, New York: Academic Press.

8. Deng, L., Turner, D.E., Gehling, R., and Prince, B. (2010). User Experience, Satisfaction, and Continual Usage Intension on IT, European Journal of Information Systems, pp. 60-75.

9. Droge, C., Halstead, D., and Mackoy, R.D. (1997). The Role of Competitive Alternative in the Post choice Satisfaction Formation Process, Journal of the Academy of Marketing Science, 25 (1), pp. 18-30.

10. Flint, D.J., Blocker, C.P., and Boutin, P.J. (2011). Customer Value Anticipation, Customer Satisfaction and Loyalty:An empirical examination, Industrial Marketing Management, 40 (2), pp. 219-230.

11. Fornell, C., Mithas, S., Morgeson III, F.V., and Krishnan, M.S. (2006). Customer Satisfaction and Stock Prices: High returns, low risk, Journal of Marketing, 70 (January), pp. 3-14.

12. Grewal, R., Chandrashekaran, M., and Citrin, A.V. (2010). Customer Satisfaction Heterogeneity and Shareholder Value, Journal of Marketing Research, 47 (4), pp. 612-626.

13. Gummerus, J. (2013). Value Creation Processes and Value Outcomes in Marketing Theory: Strangers or siblings? Marketing Theory, 13 (1), pp. 19-46.

14. Ha, H., and Tanda, S. (2008). An Empirical Test of a Proposed Customer Satisfaction Model in E-Services, Journal of Services Marketing, 22 (5), pp. 399-408.

15. Halstead, D. (1989). Cognitive and Affective Determinants of Consumer Satisfaction for a Durable Good, in Proceedings of the American Marketing Association, Bloom et al. (eds.), Chicago Illinois: American Marketing Association.

16. Hays, J.M., and Hill, A.V. (2009). The Market Share Impact of Service Failures, Production and Operations Management, 8 (3), pp. 208-220.

17. Helson, H. (1964). Adaptation Level Theory, New York: Harper and Row.

18. Hill, D.J. (1986). Satisfaction and Consumer Services, Advances in Consumer Research, 13, pp. 311-315.

19. Hunter, J.E., Schmidt, F.L., and Jackson, G.B. (1982). Meta-analysis: Cumulating Research Findings Across Studies, Beverly Hills, California: Sage Publications.

20. Hsttinger, L., Schiele, H., and Veldman, J. (2012). The Drivers of Customer Attractiveness, Supplier Satisfaction and Preferred Customer Status: A Literature Review, Industrial Marketing Management, 41, pp. 1194-1205.

21. Ivanov, V., Joseph, K., and Wintoki, M.B. (2013). Disentangling the Market Value of Customer Satisfaction: Evidence from Market Reaction to the Unanticipated Component of ACSI Announcements, International Journal of Research in Marketing, 30, pp. 168-178.

22. James, L.R., Demaree, R.G., and Mulaik, S.A. (1986). A Note on Validity Generalization Procedures, Journal of Applied Psychology, 71 (3), pp. 440-450.

23. Kennedy, J.R., and Thirkell, P.C. (1980). The Effect of Automobile Product Experience on Attribute Disconfirmation and Importance, in New Findings on Consumer Satisfaction and Complaining, Ralph L. Day and H. Keith Hunt (eds), Bloomington Indiana: Indiana University.

24. Leuschner, R., Charvet F., and Rogers, D.S. (2013). A meta-Analysis of Logistics Customer Service, Journal of Supply Chain Management, 49 (1), pp. 47.63.

25. Light, R.J., and Pillemer, D.B. (1984). Summing up: The Science of Reviewing Research, Cambridge MA: Harvard University Press.

26. Miller, J.A. (1977). Studying Satisfaction, Modifying Models, Eliciting Expectations, Posing Problems and Making Meaningful Measurements, in Conceptualization and Measurement of Consumer Satisfaction and Dissatisfaction, H. Keith Hunt (ed.), Cambridge, MA: Marketing Science Institute, pp. 72-91.

27. Mintz, O., and Currim, I.S. (2012). What Drives Managerial Use of Marketing and Financial Metrics and Does Metric Use Impact Performance of Marketing Mix Activities? Journal of Marketing, 77 (March), pp. 1-51.

28. Mishra, D.P. (1994). Total Quality Management in Health Services: Historical Development, Conceptual Meaning, and Comprehensive Model, Journal of Ambulatory Care Marketing, 5 (2), pp. 27-46.

29. Mishra, D.P. (2000a). An Empirical Assessment of Measurement Error in Health-Care Survey Research, Journal of Business Research, 48, pp. 193-205.

30. Mishra, D.P. (2000b). Interdisciplinary Contributions in Retail Service Delivery: Review and Future Directions, Journal of Retailing and Consumer Services, 7, pp. 101-118.

31. Mishra, D.P. (2006). The Role of Certification in Service Relationships: Theory and Empirical Evidence. Journal of Retailing and Consumer Services, 13 (4), pp. 81-96.

32. Mishra, D.P., Heide, J.B., and Cort, S.G. (1998). Levels of Agency Relationships in Service Delivery: Theory and Empirical Evidence, Journal of Marketing Research, 35 (3), pp. 277-295.

33. Mishra, D.P., and Min, J. (2010). Analyzing the Relationship between Dependent and Independent Variables in Marketing: A Comparison of Multiple Regression with Path Analysis. Innovative Marketing Journal, 6 (3), pp. 113-120.

34. Mullen, B. (1989). Advanced Basic Meta-analysis, New Jersey: Lawrence Erlbaum.

35. Moore, E.M., and Shuprtine, F.K. (1984). Disconfirmation Effects on Consumer Satisfaction and Decision Marking Processes, in Advances in Consumer Research, Thomas C. Kinnear (ed), Provo Utah: Association for Consumer Research. 
36. Nunnally, J.C. (1978). Psychometric Theory, New York, NY: McGraw Hill.

37. Oliver, R. (1977). Effects of Expectation and Disconfirmation on Postexposure Product Evaluations: An Alternative Interpretation, Journal of Applied Psychology, 61(2), pp. 246-250.

38. Oliver, R. (1979). Product Satisfaction as a Function of Prior Expectation and Subsequent Disconfirmation: New Evidence, in New Dimensions of Consumer Satisfaction and Complaining Behavior, Ralph L. Day, and H. Keith Hunt (eds.), Bloomington Indiana: Indiana University Press, pp. 66-71.

39. Oliver, R. (1980). A Cognitive Model of the Antecedents and Consequences of Satisfaction Decisions, Journal of Marketing Research, 17 (November), pp. 460-469.

40. Oliver, R. (1981). Measurement and evaluation of satisfaction processes in retail settings, Journal of Retailing, 57 (Fall), pp. 25-48.

41. Oliver, R., and Bearden, W.O. (1983). The Role of Involvement in Satisfaction Processes, in Advances in Consumer Research, Alice M. Tybout and Richard P. Bagozzi (eds.), Ann Arbor, MI: Association for Consumer Research.

42. Oliver, R., and Swan, J.E. (1989). Equity and Disconfirmation Perceptions as Influences an Merchant and Product Satisfaction, Journal of Consumer Research, 16 (December), pp. 372-383.

43. Oliver, R. (1993). Cognitive, Affective, and Attributes Bases of the Satisfaction Response, Journal of Consumer Research, 20 (3), pp. 418-430.

44. Orwin, R.G. (1983). A Fail-safe N for Effect Size, Journal of Educational Statistics, 8, pp. 157-159.

45. Patterson, P.G., Johnson L.W., and Spreng, R.A. (1997). Modeling the Determinants of Customer Satisfaction for Business-to-Business Professional Services, Journal of the Academy of Marketing Science, 25 (1), pp. 4-17.

46. Patterson, P.G. (2000). A Contingency Approach to Modeling Satisfaction with Management Consulting Services, Journal of Service Research, 3 (2), pp. 138-153.

47. Parasuraman, A., Zeithaml, V.A., and Berry, L.L. (1988). SERVQUAL, Journal of Retailing, 64 (1), pp. 12-40.

48. Parasuraman, A., Berry, L.L., and Zeithaml, V.A. (2004). Refinement and Reassessment of the SERVQUAL Scale, Journal of Retailing, 67 (4), p. 114.

49. Prakash, Ved. and Lounsburry, J.W. (1984). The Role of Expectations in the Determination of Consumer Satisfaction, Journal of the Academy of Marketing Science, 12 (3), pp. 1-17.

50. Rosenthal, R. (1979). The File-drawer Problem and Tolerance for Null Results, Psychological Bulletin, 86, pp. 638-641.

51. Rosenthal, R. (1984). Meta-analytic Procedure for Social Research, Beverly Hills California: Sage Publications.

52. Spreng, R.A., and Chiou, J. (2002). A Cross-Cultural Assessment of the Satisfaction Formation Process, European Journal of Marketing, 36 (7/8), pp. 829-839.

53. Swan, J.E., and Trawick, I.F. (1981). Satisfaction Explained by Desired Vs. Predictive Expectations, in Proceedings of the American Marketing Association, Bernhardt et al. (eds.), Chicago Illinois: American Marketing Association.

54. Swan, J.E., and Martin, W.S. (1981a). Testing Comparison Level and Predictive Expectations Models of Satisfaction, in Advances in Consumer Research, Kent B. Monroe (ed.), Ann Arbor Michigan: Association for Consumer Research.

55. Szymanski, D.M., and Henard, D.H. (2001). Customer Satisfaction: a Meta-Analysis of the Empirical Evidence, Journal of the Academy of Marketing Science, 29 (1), pp. 16-35.

56. Tsiros, M., Mittal, V., and Ross, Jr., W. (2004). The Role of Attributions in Customer Satisfaction: A Reexamination, Journal of Consumer Research, 31 (2), pp. 476-485.

57. Varela-Neira, C., Vazquez-Casielles, R., and Iglesias, V. (2010). Explaining Customer Satisfaction with Complaint Handling, International Journal of Bank Marketing, 28 (2), pp. 88-112.

58. Vargo, S.L., and Lusch, R.F. (2004). Evolving to a New Dominant Logic for Marketing, Journal of Marketing, 68 (1), pp. 1-17.

59. Westbrook, R.A. (1980). Intrapersonal affective influences upon consumer satisfaction, Journal of Consumer Research, 7 (June), pp. 49-54.

60. Westbrook, R.A., and Reilly, M.D. (1983). Value-Percept Disparity: An Alternative to The Disconfirmation of Expectations Theory of Consumer Satisfaction, Advances in Consumer Research, Richard P. Bagozzi and Alice M. Tybout (eds.), Ann Arbor Michigan: Association for Consumer Research.

61. Wanous, J.P., Sullivan, S.E., and Malinak, J. (1989). The Role of Judgment Calls in Meta-Analysis, Journal of Applied Psychology, 74 (2), pp. 259-264.

62. Winkler, G., and Schwaiger, M.S. (2011). Is Customer Satisfaction Driving Revenue - A Longitudinal Analysis With Evidence From The Banking Industry, Journal of Business \& Economics Research, 2 (1).

63. Yen, C., and Lu, H. (2008). Effects of E-service Quality on Loyalty Intention: An Empirical Study in Online Auction, Managing Service Quality, 18 (2), pp. 127-146.

64. Yi, Y. (1993). The Determinants of Customer Satisfaction: The Moderating Role of Ambiguity, in Advances in Consumer Research, Vol. 20, (eds.) Leigh McAlister and Michael L. Rothschild, Provo, UT: Association for Consumer Research, pp. 502-506.

65. Yi, Y. (1990). A Critical Review of Consumer Satisfaction, in Review of Marketing 1990, Valerie A. Zeithaml (ed.), Chicago IL: American Marketing Association, pp. 68-123. 


\section{Appendix}

Table 1. Characteristics of studies used in the meta-analysis

\begin{tabular}{|c|c|c|c|c|c|c|c|c|c|c|c|c|c|c|c|c|}
\hline Study & Author a & Year & $N^{b}$ & $\begin{array}{l}\text { Expectation } \\
\text { type }\end{array}$ & $n^{c}$ & $a^{\mathrm{d}}$ & $\begin{array}{l}\text { Disconfirmation } \\
\text { type }\end{array}$ & $n$ & $a$ & $\begin{array}{c}\text { Satisfaction } \\
\text { type }\end{array}$ & $n$ & $a$ & $\begin{array}{l}\mathrm{SDe} \\
\text { Disc }\end{array}$ & $r$ & $p$ & $\begin{array}{c}\text { Productf } \\
\text { type }\end{array}$ \\
\hline 1 & $\begin{array}{l}\text { Varela- } \\
\text { Neira }\end{array}$ & 2010 & 673 & $\sum g, 1$ & 3 & .94 & Sub $^{5}$ & 2 & .94 & Affect & 4 & .96 & 1.56 & .69 & .010 & Ser \\
\hline 2 & Deng & 2010 & 289 & -- & -- & -- & Sub & 4 & .95 & Affect & 3 & .95 & 1.21 & .67 & .010 & Ser \\
\hline 3 & $\mathrm{Ha}$ & 2008 & 386 & - & -- & -- & Sub & 2 & .81 & Affect & 3 & .89 & 1.01 & .58 & .050 & Dur \\
\hline 4 & Yen & 2008 & 619 & -- & -- & -- & Sub & 4 & .91 & Affect & 4 & .89 & - & .71 & .010 & Ser \\
\hline 5 & Tsiros & 2004 & 202 & & & & Sub & 1 & -- & Affect & 3 & .95 & -- & -- & -- & Ser \\
\hline 6 & Spreng & 2002 & -- & $\sum g$ & 4 & .97 & Sub & 4 & .96 & Affect & 4 & .97 & -- & .77 & .050 & Dur \\
\hline 7 & Patterson & 2000 & 128 & -- & -- & -- & Sub & 2 & .87 & Mixed & 4 & .94 & -- & .80 & -- & Ser \\
\hline 8 & Droge & 1997 & 331 & -- & -- & -- & Sub & 1 & -- & Affect & 1 & -- & - & -- & -- & Dur \\
\hline 9 & Patterson & 1997 & 128 & $\sum g$ & 26 & -- & Sub & 2 & .88 & Affect & 3 & .95 & -- & .88 & .010 & Ser \\
\hline 10 & Oliver & 1993 & 125 & -- & -- & -- & Sub & 7 & .89 & Affect & 6 & -- & 0.61 & -- & -- & Dur \\
\hline 11 & Oliver & 1989 & 184 & - & -- & -- & Sub & 3 & .84 & Mixed & 12 & .94 & 0.67 & .53 & .010 & Dur \\
\hline 12 & Halstead & 1989 & 404 & $\sum g$ & 3 & -- & Sub & 3 & -- & Mixed & 1 & -- & 1.69 & .08 & .050 & Dur \\
\hline 13 & Cadotte & 1987 & 87 & $\sum g$ & -- & -- & Sub & 1 & -- & Affect & 10 & .77 & -- & .50 & .010 & Ser \\
\hline 14 & Barbeau & 1985 & 114 & $\sum g$, & 8 & -- & Sub & 8 & -- & Mixed 6 & 10 & -- & -- & .00 & .479 & Ser \\
\hline 15 & Moore & 1984 & 183 & $\sum g$ & 14 & -- & Sub & 3 & .68 & Mixed & 3 & .89 & 2.29 & .17 & .010 & Ser \\
\hline 16 & Moore & 1984 & 207 & $\sum g$ & 14 & -- & Sub & 3 & .66 & - & 3 & .85 & 2.66 & .16 & .010 & Ser \\
\hline 17 & Prakash & 1984 & 300 & $\sum g$ & 7 & .46 & $\mathrm{Sub}^{5}$ & 7 & .19 & Mixed & 1 & -- & 3.56 & .19 & .050 & ND \\
\hline 18 & Westbrook & 1983 & 66 & $\sum g$ & 11 & -- & Sub & 2 & -- & -- & 1 & -- & 1.38 & .37 & .050 & Dur \\
\hline 19 & Bearden & 1983 & 188 & $\sum g$ & 6 & -- & Sub & 1 & -- & Mixed & 4 & .76 & 1.30 & .25 & .010 & Ser \\
\hline 20 & Bearden & 1983 & 187 & $\sum g$ & 6 & -- & Sub & 1 & -- & Mixed & 4 & .66 & 1.40 & .15 & .010 & Ser \\
\hline 21 & Churchill & 1982 & 126 & $\sum g$ & 9 & .88 & $\mathrm{Obj}{ }^{4}$ & 12 & .85 & Mixed & 25 & .87 & - & .15 & .050 & Dur \\
\hline 22 & Churchill & 1982 & 180 & $\sum g$ & 8 & .95 & $\mathrm{Obj}{ }^{4}$ & 11 & .81 & Mixed & 23 & .94 & -- & .00 & .500 & ND \\
\hline 23 & Oliver & 1981 & 250 & $\sum g$ & 9 & -- & Sub & 9 & .74 & Mixed & 3 & .94 & -- & .50 & .010 & Dur \\
\hline 24 & Oliver & 1981 & 250 & $\sum g$ & 9 & -- & Sub & 9 & .74 & Mixed & 3 & .94 & -- & .55 & .010 & Dur \\
\hline 25 & Swan & 1981 & 250 & $\sum \mathrm{h}$ & 7 & -- & Sub & 7 & -- & -- & 2 & .56 & -- & .48 & .001 & Ser \\
\hline 26 & Swan & 1981(a) & 67 & $\sum g$ & 12 & -- & Sub & 12 & -- & -- & 1 & -- & -- & .14 & .500 & Dur \\
\hline 27 & Oliver & 1980 & 291 & $\sum \mathrm{h}$ & 8 & -- & Sub & 2 & - & Affect & 8 & -- & -- & .14 & .010 & Ser \\
\hline 28 & Oliver & 1980 & 162 & $\sum \mathrm{h}$ & 8 & -- & Sub & 2 & -- & Affect & 8 & -- & -- & .18 & .010 & Ser \\
\hline 29 & Oliver & 1980 & 65 & $\sum \mathrm{h}$ & 8 & -- & Sub & 2 & -- & Affect & 8 & -- & -- & .29 & .010 & Ser \\
\hline 30 & Oliver & 1980 & 86 & $\sum \mathrm{h}$ & 8 & -- & Sub & 2 & -- & Affect & 8 & -- & -- & .25 & .010 & Ser \\
\hline 31 & Westbrook & 1980 & 156 & -- & -- & -- & Sub & -- & .65 & -- & 1 & .72 & 1.40 & .46 & .050 & Dur \\
\hline 32 & Kennedy & 1980 & 985 & $\sum g$ & 2 & -- & Sub $^{5}$ & 2 & -- & - & 1 & -- & -- & .22 & .001 & Dur \\
\hline
\end{tabular}

Notes: ${ }^{\mathrm{a}}$ Only the first author is listed; ${ }^{\mathrm{b}}$ Sample size; ${ }^{\mathrm{c}}$ No of items; ${ }^{\mathrm{d}}$ Chronbach's alpha; ${ }^{\mathrm{e}}$ Std. dev; ${ }^{\mathrm{f}}$ Type of product (service) investigated; Ser $=$ Service; Dur $=$ Durable; ND = Non-Durable; ${ }^{\mathrm{g}} \Sigma=\Sigma B_{i} ;{ }^{\mathrm{h}} \Sigma=\Sigma B_{i} a_{i} ;{ }^{1}$ Summation of belief items; ${ }^{2}$ Belief $\mathrm{x}$ Prob; ${ }^{3}$ Subj (Direct); ${ }^{4}$ Obj (Diff); ${ }^{5}$ Sub (Diff); ${ }^{6}$ Affective and Cognitive items; ${ }^{7}$ Disconfirmation without superscript refers to 3 (i.e., direct measure); ${ }^{8}$ Results for statistically independent samples have been considered as separate studies; ${ }^{9}$ Studies utilizing the same data-base have been excluded from the analysis. 